\title{
NiTi Rotary Instruments: New Investigations of Patterns of Fracture
}

\author{
Edit Xhajanka ${ }^{1}$, Federico V Obino ${ }^{2}$, Andrea Del Giudice ${ }^{3}$, Gabriele Miccoli $^{4}$, Shilpa Bandhi ${ }^{5}$, Andrea Cicconetti $^{6}$
}

World Journal of Dentistry (2021): 10.5005/jp-journals-10015-1803

Along with the introduction of nickel-titanium, endodontics has deeply changed. The switch from manual stainless-steel instruments to NiTi rotary instruments has influenced not only operative times but also shaping procedures, irrigant penetration, and obturation techniques. ${ }^{1}$ However, if some major improvements were introduced, different kinds of drawbacks appeared to happen more frequently. While SS instruments are less efficient than NiTi rotary instruments, they usually happen to separate inside the canal less often than the former ones. ${ }^{2}$ One of the main issues regarding SS files was the possibility to create a perforation inside the root. The fracture could happen because this type of file presents an active tip that, if pushed too hard over the dentinal wall of a root, can create a different path, eventually leading to perforation. On the other hand, regarding this topic, NiTi rotary instruments are overall safer since they present a noncutting tip. This is mainly because the transition angle of the file tip is designed to be non-active and therefore much safer than SS files. ${ }^{3}$ However, as previously mentioned, also NiTi instruments present some important drawbacks that have to be considered due to prevent the development of excessive stresses that are not supported by the chosen instrument. Indeed, to exalt the properties of the NiTi instrument, it is important to know the characteristics of the chosen NiTi file, not only their breakage resistance in traditional static conditions but also their behavior during clinical procedures.

Up to date, literature has individuated and deeply evaluated the flexural and torsional behavior of NiTi rotary instruments. Precisely, the cyclic fatigue stress is a mechanism that happens for every kind of metal, freely rotating inside a curvature. It is nothing less than the weakening of a material caused by cyclic loading that eventually results in progressive and localized structural damage. This continual tension and compression on the area of maximum curvature will lead to the formation of cracks that, once initiated, will not stop their progression. ${ }^{4}$

On the other hand, torsional stress occurs when the tip of the instrument binds inside the canal, while the upper part continues to rotate: this free rotation of the coronal part of the instrument will lead to separation. The instrument is often submitted to this kind of stress while advancing toward the apex.,

Literature is now trying to find more peculiar ways to investigate NiTi rotary file properties. Indeed, while some researchers tried to measure the amount of stress generated during root canal treatment (RCT), others have tried to investigate, in a static condition, different and more up-to-date properties of endodontic instruments. ${ }^{7}$

The measurement of operative torque is nowadays the most representative method for the evaluation of stresses during root canal treatment. ${ }^{8,9}$ Despite that, authors have still not found a consensus on this kind of evaluation process: it is still unclear if the separation is a representation of only torsional stresses or a sum up of both torsional and flexural fatigue and, it is unclear the
${ }^{1}$ Department of Dental Medicine, Medical University of Tirana, Rruga e Dibrës, Tirana, Albania

2-4,6 Department of Oral and Maxillo-facial Sciences, Sapienza University of Rome, Rome, Italy

${ }^{5}$ Department of Restorative Dental Sciences, Jazan University, Jazan, Kingdom of Saudi Arabia

Corresponding Author: Gabriele Miccoli, Department of Oral and Maxillo-facial Sciences, Sapienza University of Rome, Rome, Italy, Phone: +39 3880459264, e-mail: gabriele.miccoli@uniroma1.it

How to cite this article: Xhajanka E, Obino FV, Del Giudice A, et al. NiTi Rotary Instruments: New Investigations of Patterns of Fracture. World J Dent 2021;12(2):95-96.

Source of support: Nil

Conflict of interest: None

importance of clinical technique and clinician skill on operative torque. Measuring the operative torque can be obtained in different ways, with the introduction of two different values: mean torque and average peak torque. ${ }^{10}$ Therefore, it is still to standardize the measurement of this new parameter.

The bending resistance has been tested on a different portion of the instrument compared to ISO standard: this kind of approach is more representative of recently developed clinical approaches, such as less invasive access cavity which appears to be one of the main goals for minimal invasive endodontics. Indeed, a conservative access cavity would force the instrument to enter tilted into the canal and therefore it is logical that the whole instrument would develop flexural stresses. ${ }^{11}$

Overall, these patterns of fracture have a historical background of several studies, evaluating flexural or torsional resistance using a static methodology validated by ISO. However, nowadays these static evaluations must be considered obsolete and therefore, present literature is trying to move toward a dynamic evaluation of these stresses with the aim of overcome some difficulties in performing these tests and creating a large consensus among researchers.

\section{References}

1. Gambarini G, Testarelli L, Pongione G, et al. Radiographic and rheological properties of a new endodontic sealer. Aust Endod J 2006;32(1):31-34. DOI: 10.1111/j.1747-4477.2006.00005.x.

2. Reda R, Zanza A, Reda R, et al. A comprehensive in vitro comparison of mechanical properties of two rotary endodontic instruments. World J Dent 2020;11(3):185-188. DOI: 10.5005/jp-journals-10015-1729.

3. Di Nardo D, Miccoli G, Mazzoni A, et al. Centering ability of a new nickel-titanium rotary instruments with a peculiar flat-side design:

(c) Jaypee Brothers Medical Publishers. 2021 Open Access This article is distributed under the terms of the Creative Commons Attribution 4.0 International License (https://creativecommons.org/licenses/by-nc/4.0/), which permits unrestricted use, distribution, and non-commercial reproduction in any medium, provided you give appropriate credit to the original author(s) and the source, provide a link to the Creative Commons license, and indicate if changes were made. The Creative Commons Public Domain Dedication waiver (http://creativecommons.org/publicdomain/zero/1.0/) applies to the data made available in this article, unless otherwise stated. 
an in vitro study. J Contemp Dent Pract 2020;21(5):539-542. DOI: 10.5005/jp-journals-10024-2829.

4. Di Nardo D, Gambarini G, Seracchiani M, et al. Influence of different cross-section on cyclic fatigue resistance of two nickel-titanium rotary instruments with same heat treatment: an in vitro study. Saudi Endod J 2020;10(3):221-225.

5. Gambarini G, Seracchiani M, Zanza A, et al. Influence of shaft length on torsional behavior of endodontic nickel-titanium instruments. Odontology 2020. DOI: 10.1007/s10266-020-00572-2Online ahead of print.

6. Gambarini G, Miccoli G, Di Nardo D, et al. Torsional resistance of two new heat treated nickel titanium rotary instruments: an in vitro evaluation. Pesqui Bras Odontopediatria Clin Integr 2020;20:1-7.

7. D'Angelo M, Del Giudice A, Mazzoni A, et al. Fatigue resistance of two nickel-titanium rotary instruments before and after ex vivo root canal treatment. J Contemp Dental Pract 2020;21(7):728-732. DOI: 10.5005/ jp-journals-10024-2875.

8. Di Nardo D, Seracchiani M, Mazzoni A, et al. Torque range, a new parameter to evaluate new and used instrument safety. Appl Sci 2020;10(10):3418. DOI: 10.3390/app10103418.

9. Mazzoni A, Pacifici A, Zanza A, et al. Assessment of real-time operative torque during nickel-titanium instrumentation with different lubricants. Appl Sci 2020;10(18):6201. DOI: 10.3390/ app10186201.

10. Seracchiani M, Miccoli G, Di Nardo D, et al. Effect of flexural stress on torsional resistance of NiTi instruments. J Endod 2020;47(3):472-476. DOI: 10.1016/j.joen.2020.10.011

11. Miccoli G, Cicconetti A, Gambarini G, et al. A new device to test the bending resistance of mechanical endodontic instruments. Appl Sc 2020;10(20):1-6. DOI: 10.3390/app10207215. 